\title{
Perception, management and pharmacoeconomics of breast cancer in the North West region of Cameroon
}

\author{
Mercy Akwi Mbacham TAH-MONUNDE ${ }^{1}$, Joseph CHENJO $^{1,2}$, \\ Kenneth Anchang YONGABI ${ }^{1}$, Charles FOKUNANG ${ }^{3}$, Wilfred Fon MBACHAM ${ }^{4, *}$ \\ ${ }^{I}$ Department of Health Economics, Policy and Management, Catholic University of Cameroon, Cameroon. \\ ${ }^{2}$ World Bank Mission Yaounde, Cameroon. \\ ${ }^{3}$ Department of Pharmaco-toxicology and Pharmacokinetics, Faculty of Medicine and Biomedical Sciences, \\ University of Yaoundé 1, Cameroon. \\ ${ }^{4}$ University of Yaoundé 1, Cameroon. \\ ${ }^{*}$ Corresponding author; E-mail: wfmbacham@yahoo.com
}

MAMT-M is very grateful to the Fobang Foundation Yaoundé, Cameroon for the financial assistance.

\begin{abstract}
Breast cancer $(\mathrm{BC})$ is the second most commonly diagnosed cancer worldwide, with an annual incidence of about 1.7 million (11.9\%). In Africa and Cameroon, BC accounts for $28 \%$ and $33.4 \%$ respectively of all cancers, hence it is a health and an economic burden. This study was conducted to investigate the perception and practice of breast self-examination among breast cancer patients, evaluate the pharmacoeconomics of chemotherapy against phyto-therapy and to relate these to the stage of presentation at hospital. A cross-sectional survey was carried out on 75 tradi-practitioners in the North West Region who treat BC and on 85 BC patients who attended the Regional Hospital Bamenda. Pharmacoeconomic analyses were done on the cost of treatment of $\mathrm{BC}$ using each of the health interventions. The structured questionnaires had four sections labelled A through D. Section A of both questionnaires demanded background information from the participants such as their location (village), type of community, the date of interview and the consent; Section B demanded demographic characteristics of the participants; Section $\mathrm{C}$ was concerned with the management of breast cancer; Section D contained questions whose responses enabled the researcher to calculate the cost of treatment. From the study, $15.3 \%$ of respondents knew and practised BSE. The mean delay before presentation for medical evaluation was 10.9 months for those who knew and practiced BSE, the average costs of treating BC by chemotherapy and by phyto-therapy were $\$ 3,042$ and $\$ 1,500$ respectively. We conclude that BSE greatly influences the stage of presentation of BCPs at the hospital for consultation, with those who know and practise it having a lower mean delay of presentation at the hospital for treatment. We also conclude that the treatment of breast cancer using plant preparations is apparently less costly than by conventional chemotherapy but with no evidence in the delay of time-to-metastasis.
\end{abstract}

(C) 2020 International Formulae Group. All rights reserved.

Keywords: Knowledge, pharmacoeconomics, breast cancer, breast self-examination, chemotherapy, phytotherapy

\section{INTRODUCTION}

Breast cancer is the second most commonly diagnosed cancer worldwide with 1.7 million cases annually $(11.9 \%)$, second to lung cancer with (1.8 million cases annually $(13.0 \%)$ as stated by the International Agency for Research on Cancer (IARC, 2013), hence constitutes a serious public health concern. It is 
the most common cause of cancer death among women (522,000 annually) in 140 out of 184 countries worldwide, especially among women aged 50 and above (Ekwueme et al., 2014). Stephanie (2014) reports that young women less than 40 years old are likely to die of the disease than older women greater than 50 years, although the disease is more prevalent among older women. In Africa, breast cancer accounts for $28 \%$ of all cancers and $20 \%$ of all cancer deaths in women, Joe-Nat (2017). In Cameroon, breast cancer is the most common of all cancers (MINSANTE, 2017), with a prevalence of $33.4 \%$ (Doh, 2010). Enow et al. (2012) revealed that cancer of the breast topped the list among the commonest cancers found in Cameroon, with 837 new breast cancer cases diagnosed in females and 32 in males, during the period 2010 - 2011 thus; representing $18.5 \%$ of all cancer cases (2012). It is the underlying cause of deaths in Cameroon and accounts for 1382 deaths $(0.63 \%)$ of total annual deaths (WHO, 2017).

Breast cancer deaths in developing countries result mainly from delayed presentation for medical evaluation, as a result of lack of awareness, prolonged denial, religious beliefs, and consultation with herbal tradi-practitioners, among others (Adesunkanmi et al., 2006; Anyanwu, 2008). Attendance of breast cancer patients to the hospitals at a relatively advanced stage, coupled with the inadequacy of medical technology for cancer screening, diagnosis and clinical management in developing countries further compounds the problem (Ekotarh et al., 2007). Considering these limited diagnostic and clinical facilities available to most breast cancer patients, early diagnosis and prevention remains the cornerstone in the fight against the disease. Secondary prevention of the disease can be achieved through an early detection by screening as recommended by the Cameroon's National Cancer Control Committee (NCCC, 2007). The NCCC obliges women of age 20 and above to examine their breasts once every month, 3-5 days after each menstrual period. This technique called breast self-examination
(BSE) and involves visual inspection in the mirror, of the nipple and the entire breast and palpation. The guideline further adds that women who are no longer menstruating should establish a routine of examining their breasts on the same date of every month (NCCC, 2007). Although BSE has not been shown to be effective in reducing mortality, this method is still recommended as a general approach to increasing breast health awareness and thus allows for early detection of any anomalies (Ginsberg et al., 2012). Furthermore, BSE continues to be recommended by health care practitioners because it is free, painless and easy to practice (Suh et al., 2012). Having a sound knowledge of the practice of BSE could be useful in the design of interventions aimed at preventing $\mathrm{BC}$ through increased awareness and /or screening. Unfortunately, many people are ignorant of BSE as a preventive method of breast cancer control. In most developing countries, the resources available for delivering primary healthcare services are limited in supply in relation to the demand for healthcare needs. This necessitates carrying out economic analyses to determine which health intervention(s) will provide the highest benefits for the resources expended (CataláLlópez et al., 2011). There is also the need to carry out economic analyses to assess the facts that underlie the benefit and harm of a healthcare intervention. Through the use of clinical epidemiological and economic data, a comparative analysis can be effected on the alternative actions in terms of cost and health outcomes (Catalá-Llópez et al., 2011).

The cost of various conventional therapies for breast cancer scares some patients from attending hospitals. These persons resort to phyto-therapy which they perceive as readily available and which may be ineffective or even toxic. They only visit hospitals when the herbal options have failed, often too late to alleviate the damage. The motivation to investigate phyto-therapy use as an alternative source in breast cancer therapy stems from the fact that in Cameroon the result of long economic asphyxiation due to multiple currency 
devaluation, less access to conventional treatment and poverty of the population, have led more people in the local communities to develop an interest in herbal therapy. Cameroon is no doubt endowed with a rich biodiversity of medicinal plants which give readily available products with a long history of ethno-botanic uses and considerations.

This study was conducted to investigate the perception and practice of breast selfexamination among breast cancer patients and to evaluate the differential cost of treatment of breast cancer by chemotherapy and by traditional phyto-therapy. It was hypothesized that there is no significant difference in the cost of treatment of breast cancer either by chemotherapy or by phyto-therapy.

\section{MATERIALS AND METHODS}

\section{Ethical consideration and data collection}

Authorization to conduct this study was obtained from the Research Directorate of the Catholic University of Cameroon (59411/4/4/16/CATUC), Bamenda and the Regional Delegation of Public Health, N. W. Region, Cameroon (424/RA/NWR/RDPH).A cross sectional study was conducted by structured questionnaires, to evaluate the perception and practice of breast-selfexamination among 85 breast cancer patients who attended the Regional Hospital Bamenda (RHB) and herbal clinics. Another survey was conducted among 75 tradi-practitioners in NW Region, Cameroon in the period, 2015-2016. Informed consent was obtained from the respondents who read, approved and signed a copy of the consent form. For patients or tradipractitioners who were unable to read and/or write, the researcher or an interpreter, interpreted the questions in the local language or pidgin English and wrote down the responses. For those unable to write, thumb prints were used for consenting. Using data from the two surveys, the relationship between the knowledge and practice of BSE and the stage at which the breast cancer patients presented themselves for medical evaluation was established. The claims made by those who resorted to phyto-therapy for the treatment of breast cancer raised two concerns - Was it really less costly and effective to treat breast cancer by phyto-therapy and which of the two interventions saved cost and was better at improving health outcomes? These two observations led to the study design of patients attending the NW Regional Hospital Bamenda and tradi-practitioners who treated breast cancer within the seven divisions of the North West Region of Cameroon.

The structured questionnaires had four sections labelled A through D. Section A of both questionnaires demanded background information from the participants such as their location (village), type of community, the date of interview and the consent; Section B demanded demographic characteristics of the participants; Section $\mathrm{C}$ was concerned with the management of breast cancer; Section D contained questions whose responses enabled the researcher to calculate the cost of treatment. Characteristics included age, level of education, length of time patient has been suffering from the $\mathrm{BC}$, her occupation, the number of days a week she was away from work due to the disease and the number of caregivers she had and their occupation, their perception of breast cancer and breast selfexamination. The questions on the cost demanded responses on the frequency and length of consultation/treatment, the amount charged for consultation, laboratory tests and drugs for each patient; the frequency and length of hospitalization, the cost of hospitalization per night and cost of feeding. The responses enabled the cost of treating BC to be evaluated. For the traditional care provider, the questionnaire requested information on his/her treatment practices such as, whether he/she was full-time or part-time tradi-practitioner, number of people working with him/her, number of patients per day who attended his/her health facility, where the patients came from, the type of cancer he/she treats, other diseases he/she treats and the stage at which the breast cancer patients presented themselves at his/her healthcare facility for consultation, 
ethno-botanic characteristics, the type of medicinal plant used, where and how they were obtained, how long they took to mature, the stage of growth at which they were harvested, the geographical condition under which the herbs were grown. Questions also demanded methods used in identifying the herbs, the part of the herb administered to patients, the method and frequency of harvesting the herbs and their preservation and their common uses in the community. Questions on the cost of treatment elicited responses on the following variables: the duration of consultation of patients, the consultation fees, the cost of herbal medicine, the frequency of payment, cost of in-patient service per night, daily cost of feeding (if provided by the tradi-practitioner). The variables were coded and known only to the team members.

\section{Cost evaluation of therapies}

Data from both questionnaires were collected; inputted using MS Excel version 2016, and analyzed statistically using Rsoftware and the Statistical Package for the Social Sciences (SPSS) version 21. The total cost and average cost of each variable was computed for the two interventions for all the respondents using the formulae:

Total Cost, $\mathrm{TC}=\sum_{\substack{v=1 \\=n}}=(\mathrm{Cv} 1+\mathrm{Cv} 2+\ldots \ldots .+$ Cvn) (1);

Where TC stands for total cost of each variable; $\mathrm{Cv}$ stands for cost of each variable; $\mathrm{n}$ stands for number of participants; $v 1=$ first value of $n$;

\section{Average Cost, $\mathrm{MC}=(\mathrm{TC}) / \mathbf{n}$}

Where MC stands for average cost of each variable.

According to the World Bank, the Gross National Income per capita for Cameroon in 2016 was 1.400 FCFA (World Bank, 2016). At that time, the market price of the dollar was 620.80 FCFA, implying that the GNI per capita for Cameroon in 2016 was 2.26USD. Income lost by breast cancer patients and care-givers at a working age as a result of the disease were estimated as follows:

Per capita income lost per day = GNI per capita $=2.26 \mathrm{USD}$.
For D days of work that will be lost by breast cancer patient/care-giver; the total income lost per patient or care-giver would be $=(2.26 \mathrm{USD}) \times \mathrm{D}$

Total Income Lost $=$ number of breast cancer patients $(\mathrm{N}) \times$ total income lost per patient and care giver

TIL $=\mathbf{N} \times$ GNIxD

The t-test was conducted to determine whether there was a significant difference between the means of the two groups. Analysis of Variance (ANOVA) was used to calculate Fvalues and compare the variances between and within the means. The $\mathrm{p}$-value for the $\mathrm{F}$ statistics for both chemotherapy and phytotherapy datasets were set at $\mathrm{p}<0.05$.

\section{RESULTS \\ Demographic characteristics of respondents}

The study took place in the NW Region of Cameroon. The 85 breast cancer patients involved in this study were all females drawn from urban (32) and rural (48) milieu. A few of them (5) did not indicate their area of residence.

\section{Age range of respondents}

Their ages ranged between 20 and 81 years, with 31 females or (36.5\%) being in the 41-50 age range. Two of the patients did not provide information on their ages (Table 1).

\section{Educational background of Breast Cancer Patients}

It turned out that $16(22.9 \%)$ had no formal education. The rest of the population had either, a primary $(29,41.4 \%)$, secondary $(18,25.7 \%)$ or tertiary $(7,10 \%)$ education (Figure 1).

\section{Occupation of Breast Cancer Patients}

Eight (11\%) females reported to have no jobs and were housewives, of whom two were on retirement $(2.7 \%)$. The rest were in some form of regular employment with a monthly income. Half of those with a gainful employment were farmers $(32,43.8 \%)$. Some twelve (14.1\%) participants did not indicate their occupation. 
Perception of breast cancer and breast selfexamination (BSE)

Of the 85 BCPs, only $16(18.8 \%)$ had knowledge of BSE. Some 69 (81.2\%) had no idea of BSE. Of the 16 who had knowledge of BSE, 09 (42.9\%) knew it through the media (radio and TV), 04 (19.1\%) from the hospital, $02(9.5 \%)$ from a friend/neighbor. For those who knew of BSE, 13 (15.3\%) of them practised it; 05 (5.9\%) weekly, 07 (8.2\%) monthly and $01(1.2 \%)$ practised it once every 2 months (Table 2). Only $8.2 \%$ of those who practised BSE, did it on a monthly basis.

\section{Time interval before presentation at a hospital}

The Breast Cancer Staging Manual (AJCC, 2010) categorizes breast cancer tumours based on the size of the tumour thus: Stage I $(x \leq 2 \mathrm{~cm})$, Stage II $(2<x<5 \mathrm{~cm})$, Stage III $(x>5 \mathrm{~cm})$. Based on this categorization, the time interval between observing a lump or mass in the breast and presentation at the hospital for consultation in this study was found to range between 0 to 6 months. It was observed that the longest waiting time was 18.8 months in the group with no knowledge or practice of BSE and a mean delay before presentation for medical evaluation of 10.92 months for the group that knew and practiced BSE (Table 3).

\section{Cost of treatment of breast cancer by chemotherapy}

The average cost in the treatment of breast cancer by conventional chemotherapy in the NWR was $\$ 3042$ with the highest possible expenditure of $\$ 5942$. The lowest cost on average paid was $\$ 18$ paid as consultation fee (Table 4). Drugs cost the most of all incurred expenses varying between $\$ 1901$ and $\$ 4282$.

\section{Cost of treatment of breast cancer by phyto-therapy}

The direct non-medical cost due to lost productivity of BCP and her care-giver is $\$ 377.91$. The lowest cost of $\$ 4.26$ was spent on consultation. The cost of treatment by tradipractitioners was $\$ 41.13$ although sometimes it was reported as being $\$ 514.57$ spent on the herbs or medicinal plant preparations (Table 5). Though average total cost of phyto-therapy stood at $\$ 1500$, patients reported paying as high as $\$ 5854$.

\section{Pharmacoeconomic analysis}

The totals for each variable and the total expenditure for $\mathrm{BCP}$ and $\mathrm{TP}$ were tested for uniformity of distribution. The distribution for the two treatment regimes are shown in Figure 2.

From Figures $2 \mathrm{~A}$ and $\mathrm{B}$, the cost of treatment for chemotherapy followed a normal distribution while that for phyto-therapy was skewed due to non-standardized cost of treatment items and the lack of diagnostic procedure. The dataset for tradi-practitioners had to be normalized so as to render it suitable for analysis. This was done by squaring the responses of the respondents. A correlation test was carried out on the two datasets to determine the significant variables in each. When the 10 variables were taken into consideration in the statistical analysis, the average cost of treatment of breast cancer by conventional therapy with the intention-to-treat (ITT) stood at $\$ 3,042$. Although the analysis yielded a range in average total cost of treatment of breast cancer by herbal preparations (PT) of between $\$ 223.83$ and $\$ 5853.58$, the cost per head stood at almost half that of conventional therapy at $\$ 1499.5$.

\section{Comparison of cost of treatment of BC by chemotherapy and by phyto-therapy}

Table 6 shows a comparison of the cost on each of the variables involved in the treatment of $\mathrm{BC}$ by chemotherapy and phytotherapy. 
Table 1: Age range of the respondents.

\begin{tabular}{lcc}
\hline Age (years) & Number of BCPs & $\%$ \\
\hline $10-20$ & 1 & 1.18 \\
$21-30$ & 4 & 4.71 \\
$31-40$ & 9 & 10.58 \\
$41-50$ & 31 & 36.46 \\
$51-60$ & 29 & 34.12 \\
$61-70$ & 4 & 4.71 \\
$71-80$ & 4 & 4.71 \\
$>81$ & 1 & 1.18 \\
Total & 83 & 97.65 \\
No information provided & 2 & 2.35 \\
\hline
\end{tabular}

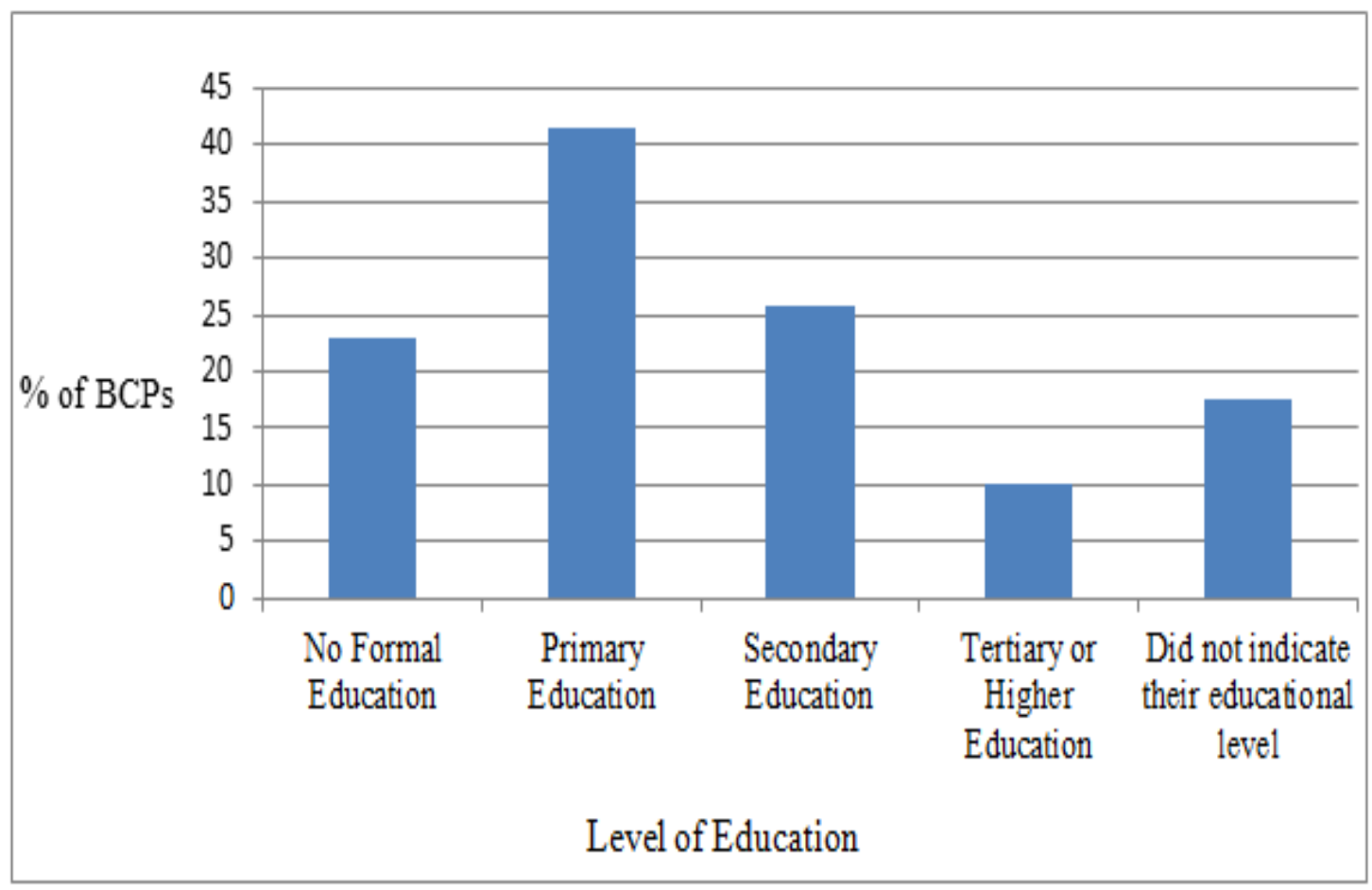

Figure 1: Educational background of breast cancer patients. 
Table 2: Perception of breast cancer and practice of breast self-examination.

\begin{tabular}{llc}
\hline \multicolumn{2}{c}{ Parameter } & Percentage o \\
\hline A (i) Knowledge of BSE: & & \\
& Yes & 18.8 \\
& No & 81.2 \\
& & 100.0
\end{tabular}

A (ii) Source of information:

$\begin{array}{cc}\text { Radio } & 56.3 \\ \text { Hospital } & 25.0 \\ \text { Friend/Neighbor } & 12.5 \\ & 93.8 \\ \text { None Respondent } & 6.2 \\ & 100.0\end{array}$

B (i) Knowledge and practice of BSE:

Knew and practiced

Knew but did not practice

Neither knew nor practiced

100.0

B (ii) Frequency of practice of BSE:

$\begin{array}{cc}\text { Weekly } & 5.9 \\ \text { Monthly } & 8.2 \\ \text { Every 2 months } & 1.2 \\ & 15.3\end{array}$

$\overline{B C P s}=$ Breast cancer patients, $B S E=$ Breast Self-Examination

Table 3: Stage of presentation and practice of BSE.

\begin{tabular}{ccccc}
\hline $\begin{array}{c}\text { Stage } \\
\text { (tumour size) }\end{array}$ & $\begin{array}{c}\text { Time Interval before } \\
\text { presentation at the } \\
\text { hospital (months) }\end{array}$ & $\begin{array}{c}\text { Knew and } \\
\text { Practiced BSE }\end{array}$ & $\begin{array}{c}\text { Knew but did not } \\
\text { Practice BSE }\end{array}$ & $\begin{array}{c}\text { Neither knew nor } \\
\text { Practiced BSE }\end{array}$ \\
\hline I $(\mathrm{x} \leq 2 \mathrm{~cm})$ & $0-6.0$ & 02 & 00 & 00 \\
$\mathrm{II}$ & $6.1-12.0$ & 06 & 01 & 13 \\
$(2 \mathrm{~cm}<\mathrm{x}<5 \mathrm{~cm})$ & $12.1-24.0$ & 05 & 02 & 31 \\
$\mathrm{III}(\mathrm{x}>5 \mathrm{~cm})$ & $24.1-48.0$ & 00 & 00 & 24 \\
\cline { 2 - 5 } & $48.1-60.0$ & 00 & 00 & 01 \\
\hline
\end{tabular}


Tables 4: Cost of treatment of breast cancer by chemotherapy.

\begin{tabular}{|c|c|c|c|c|c|c|c|c|c|c|c|}
\hline & $\begin{array}{l}\text { TRPT } \\
\text { EXP }\end{array}$ & $\begin{array}{c}\text { CONS. } \\
\text { FEE }\end{array}$ & $\begin{array}{l}\text { LAB. } \\
\text { FEE }\end{array}$ & $\begin{array}{l}\text { BLD. } \\
\text { TRAN }\end{array}$ & DRUGS & BD.FEE & FD. CP & FD. CG & $\begin{array}{c}\text { LTP. } \\
\text { CP }\end{array}$ & LTP. CG & TOTAL \\
\hline $\begin{array}{l}\text { Average } \\
\text { (US Dollars) }\end{array}$ & 40.70 & 18.03 & 19.74 & 33.46 & $1,901.11$ & 21.55 & 49.61 & 59.58 & 474.24 & 421.64 & $3,041.58$ \\
\hline $\begin{array}{l}\text { Min. Cost } \\
\text { (US Dollars) }\end{array}$ & 9.59 & 5.14 & 3.42 & 17.13 & 154.19 & 11.99 & 11.99 & 11.99 & 30.83 & 51.39 & 483.95 \\
\hline $\begin{array}{l}\text { Max. Cost } \\
\text { (US Dollars) }\end{array}$ & 137.04 & 41.11 & 171.29 & 68.51 & $4,282.31$ & 102.77 & 126.79 & 205.60 & 1.973 .85 & $1,651.64$ & $5,941.63$ \\
\hline
\end{tabular}

Tables 5: Cost of treatment of breast cancer by phyto-therapy.

\begin{tabular}{lcccccccc}
\hline & $\begin{array}{c}\text { TRPT } \\
\text { EXP }\end{array}$ & CONS.FEE & $\begin{array}{c}\text { CST. } \\
\text { TRT }\end{array}$ & FD. CP & FD. CG & LTP.CP & LTP. CG & TOTAL \\
\hline $\begin{array}{l}\text { Average (US } \\
\text { Dollars) }\end{array}$ & 75.46 & 4.26 & 41.14 & 308.76 & 293.26 & 398.49 & 377.91 & $1,499.47$ \\
\hline $\begin{array}{l}\text { Minimum } \\
\text { Cost (US } \\
\text { Dollars) }\end{array}$ & 23.15 & 0.85 & 8.48 & 25.72 & 25.72 & 51.45 & 51.45 & 223.83 \\
\hline $\begin{array}{l}\text { Maximum } \\
\begin{array}{l}\text { Cost (US } \\
\text { Dollars) }\end{array}\end{array}$ & 288.15 & 56.60 & 514.57 & 926.24 & $1,852.36$ & $1,234.91$ & $2,469.72$ & $5,853.58$ \\
\hline
\end{tabular}

TrptExp = Transport Expenses, Cons Fee $=$ Consultation Fee, CstTrt $=$ Cost of Treatment, FDCP $=$ Cost of Feeding of Breast Cancer Patients, FDCG $=$ Cost of Feeding of Caregivers, LT.P.CP $=$ Lost Productivity of Breast Cancer Patients, LT.P.CG = Lost Productivity of Caregivers. $N=51$

A - Chemotherapy

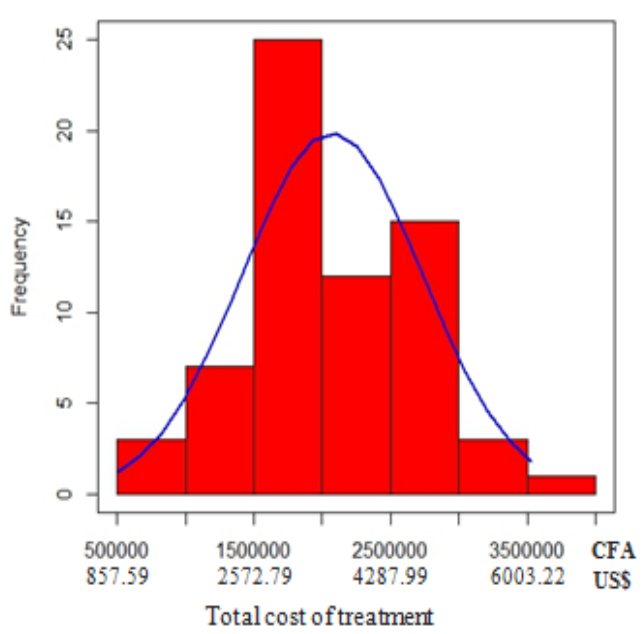

B- Phyto-Therapy

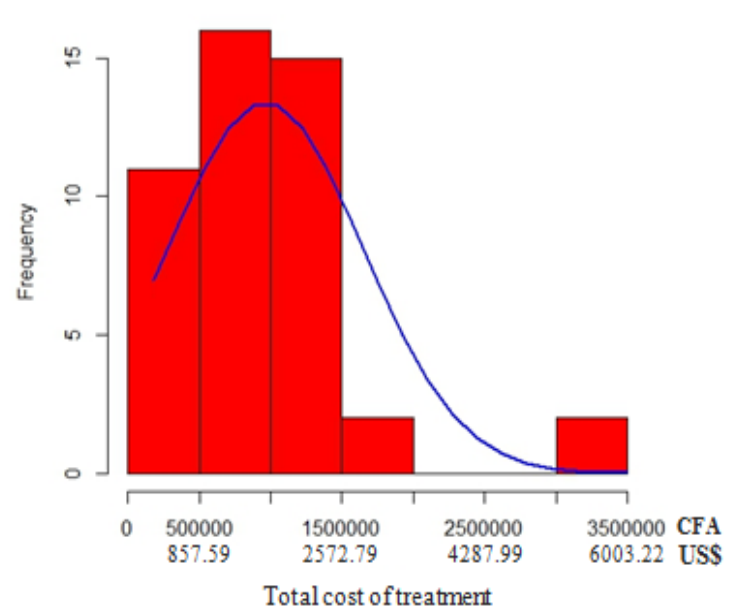

Figure 2: Distribution of total cost of treatment for breast cancer. 
Table 6: Comparison of Cost of Treatment of Breast Cancer by Chemotherapy and Phyto-therapy.

\begin{tabular}{|c|c|c|c|c|}
\hline \multirow{2}{*}{ Variables } & $\begin{array}{c}\text { Chemotherapy } \\
(\mathbf{n}=\mathbf{8 5})\end{array}$ & $\begin{array}{l}\text { Phyto-therapy } \\
(n=75)\end{array}$ & Stats & Stats \\
\hline & $\begin{array}{l}\text { Total Cost(US } \\
\text { Dollars) }\end{array}$ & $\begin{array}{l}\text { Total Cost(US } \\
\text { Dollars) }\end{array}$ & $\begin{array}{c}\text { p-value for } \\
\text { Chemotherapy }\end{array}$ & $\begin{array}{c}\text { p-value for } \\
\text { Phytotherapy }\end{array}$ \\
\hline Transport Expenses & $3,462.55$ & $5,657.68$ & 0.6188 & 0.01027 \\
\hline Consultation Fee & $1,534.05$ & 319.91 & 0.0001911 & 0.6682 \\
\hline Laboratory Fee & $1,678.76$ & 0 & 0.0116 & 0 \\
\hline Blood Transfusion Cost & $2,846.76$ & 0 & $7.54 \mathrm{e}-5$ & 0 \\
\hline Cost of Drugs & $161,675.04$ & 3.084 .31 & $2.063 \mathrm{e}-6$ & 0.1688 \\
\hline $\begin{array}{l}\text { Bed Fee } \\
\text { (Hospitalization) }\end{array}$ & $1,833.16$ & 0 & 0.7127 & 0 \\
\hline Feeding of BCPs & $44,215.23$ & $23,142.87$ & 0.0001462 & $2.2 \mathrm{e}-6$ \\
\hline Feeding of Care-giver & $5,062.40$ & 21,977.28 & $2.599 \mathrm{e}-3$ & $2.2 \mathrm{e}-6$ \\
\hline $\begin{array}{l}\text { Lost Productivity of } \\
\text { BCPs }\end{array}$ & $40,295.41$ & $29,862.63$ & $9.738 \mathrm{e}-5$ & $3.8 \mathrm{e}-6$ \\
\hline $\begin{array}{l}\text { Lost Productivity of } \\
\text { Care-givers }\end{array}$ & $35,827.86$ & $28,318.22$ & $1.832 \mathrm{e}-6$ & $3.7 \mathrm{e}-6$ \\
\hline TOTAL & $258,444.0$ & $112,358.62$ & & \\
\hline Cost per capita & $3,040.51$ & $1,498.19$ & & \\
\hline
\end{tabular}

\section{DISCUSSION}

The results of this study showed that the practice of BSE was lacking among the female population with less than one fifth of the females understanding what to do. This finding differs from those of Suh et al. (2012) who found that $36.6 \%$ of the respondents recognized, knew and practised BSE as a method of preventing breast cancer in Buea, South West Region of Cameroon. In another town, Limbe $20 \mathrm{~km}$ away from Buea, the Health Education and Research Organization (HERO) Cameroon in 2017 demonstrated that less than $15 \%$ of the participants had heard of BSE and less than $5 \%$ practised BSE (HERO, 2017). Similarly, the lower value of BSE obtained in this study could not be attributed to the low academic background of the participants since most of them had some formal education of at least a primary education. Isara and Ojedokun reported of their study among female Senior Secondary School Students in Abuja, Nigeria that, a high proportion of the respondents knew about BSE as a method of preventing breast cancer but only one tenth of them practiced it (Isara and Ojedokun, 2011). In a similar survey carried out on 300 women in Dakar, Senegal, Geuye et al., reported that $42.7 \%$ of the respondents knew BSE but only 29\% practised it (Gueye et al., 2009). The time interval between observing a lump (Stage 1) and attendance at the hospital for consultation ranged from 0 month to 48 months for those who practised BSE with a mean delay of 11 months, closer in value to the finding of Kemfang et al. (2011) which was 
10.35 months among patients who attended the Radiation Therapy Unit of Yaoundé General Hospital. Ginsberg et al. (2012) affirmed that BSE allows for early detection of anomalies.

Results obtained herein demonstrate that, there is a significant difference in the cost of treatment of BC by chemotherapy and by the use of medicinal plants. The average costs of treating breast cancer by chemotherapy in the NW region was found to be US $\$ 3,0681.51$ ( $\mathrm{n}=$ 85) comparable to the finding of (NCCC, 2010), which revealed that the cost of treating BC by chemotherapy is US\$ 3,601.31 2.1 (2.1 million FCFA). Considering the fact that the GNI per capita figures for Cameroon were \$852, \$836 and \$913 in the years 2015, 2016 and 2017 respectively (IMF, 2015), these costs were far above what an average Cameroonian could pay. It would require savings of total income for at least three years before a female can have treatment by chemotherapy. During this period, the disease would have even progressed to a more dangerous stage. The above costs are more than three times the GNP per capita of Cameroon. Based on the observations of the Commission on Macroeconomics and Health, WHO (2015), the treatment of breast cancer by chemotherapy is not cost-effective compared to phyto-therapy. The cost by phyto-therapy would be better if the effectiveness of phyto-medicines in the delay of metastasis in breast cancer is proven.

This cost of treatment of breast cancer by chemotherapy from our findings was considerably low when compared with the cost of treatment of breast cancer in USA and Britain but higher than the cost of treatment in Israel, Germany, India, Thailand or Turkey (Marj \& Stanton, 2012). The Susan G. Komen Foundation estimated an average lifetime per patient treatment cost of $£ 22.000$ to manage early stages of breast cancer and over $£ 120.000$ at stages III and IV of the disease similar to a Medicare Analysis which valuated an average of $£ 110,000$ as direct lifetime cost per patient for patients with metastatic breast cancer (Pinder, 2015). The updated medical review conducted by Fahad in 2019 revealed the following as the cost of treating early stages of breast cancer by chemotherapy: US $\$ 2,800$ in
Israel and Germany, US\$2,160 in Thailand, US\$ 2,000 in Turkey, US\$ I, 100 in India (Marj, 2012). Reports of $\$ 16.5$ billion as the global cost of treating breast cancer by chemotherapy in USA in 2010 would be $\$ 20.5$ billion by 2020 and would far exceeds what developing countries could ever afford. Even though chemotherapy had greatly contributed to increasing the life expectancy of patients with breast cancer, a cure for the disease is still far from being achieved, especially when it is at the advanced stages. The easier and cheaper way is to detect the disease at an early stage through BSE and mastectomy. Evidence presented herein revealed that the non-practice of BSE is due to lack of awareness and to the lack of knowledge on how to do it and corroborates the findings of HERO (2019). Observations contained herein point to the reinforcement of the education of the population in Cameroon through frequent dissemination of information on BSE on the print and audio-visual media, social media platforms, internet websites, bill boards, road sign posts, posters, visual-aided talks in schools, villages gatherings and churches etc, to give it the widest publicity. There needs to be a Cancer registry and special assistance to tradi-practitioners on the evaluation of the effectiveness of phyto-therapy. A formal restructuring of herbal medical practice needs to be done to provide safe options and even further reduce the cost of treatment of breast cancer by phyto-therapy.

It was observed that there was a low turnout of breast cancer patients at the main public medical institution in the North West Region that caters for breast cancer patients. In addition, the number of BCPs who started with phyto-therapy and ended up being treated by chemotherapy could not be effectively assessed. There exist no National Cancer Registry in Cameroon to have extracted statistics on breast cancer for the 10 regions of Cameroon and coupled with the lack of data on the standardized national cost of treatment of breast cancer in Cameroon stemmed out to be the limitations of this study. It is probable that the cost would further be higher if these cancer patients received radiotherapy in Yaounde or 
Douala where these centres exist equally with the cost of treatment and which was not the case for Bamenda. Whether these patients stayed well more on one group or the other was not assessed.

\section{Conclusion}

From the study, it was concluded that BSE greatly influences the stage of presentation of BCPs at the hospital for consultation, with those who know and practise it having a lower mean delay of presentation at the hospital for treatment. It was also concluded that the treatment of breast cancer using plant preparations is apparently less costly than by conventional chemotherapy but with no evidence in the delay of time-tometastasis. Breast cancer patients who present themselves at an earlier stage are less likely to progress towards metastasis especially as BSE is free, painless and easy to practise.

\section{COMPETING INTERESTS}

The authors declare that they have no competing interests.

\section{AUTHORS' CONTRIBUTIONS}

MAMT-M conceived the study design, interviewed the participants, wrote the manuscript and did statistical analysis. WFM conceived the protocol, did statistical analysis and reviewed the manuscript and article. KAY participated in the write up and reviewed the article. $\mathrm{CF}$ and JC reviewed the manuscript.

\section{ACKNOWLEDGEMENTS}

We are equally indebted to the North West Regional Hospital for data concerning BCPs. We are equally indebted to the tradipractitioners and patients who volunteered information, as well as some herbal clinics that granted access to data.

\section{REFERENCES}

Adesunkanmi AR, Lawal OO, Adelusola KA, Durosimi MA. 2006. The severity, outcome and challenges of breast cancer in Nigeria. The Breast Journal, 15(3): 399-409.

American Joint Committee on Cancer. 2010.
Breast Cancer Staging Manual (7th edn). Springer: New York; 347-369.

Anyanwu NCS. 2008. Temporal trends in breast cancer presentation in the third world. Journal of Experimental and Clinical Research, 27(1): 17-22.

Catalá-Llópez F, García-Altés A, AlvarezMartín E, Gènova-Maleras R, MorantGinestar C, Parada A. 2011. Burden of disease and economic evaluation of healthcare interventions: are we investigating what really matters? $B M C$ Health Services Research, 11(75). DOI: 10. 1186/1472-6963-11-75.

Doh A. 2010. The diagnosis and treatment of cancer costs about FCFA 2.1 million experts say, Paper presented at the NCCC Symposium.

Ekortarh AC, Ndom P, Sacks A. 2007. A study of patients who appear with advanced cancer at Yaounde General Hospital, Cameroon, Africa. Psycho-Oncology, 16(3): 1-3.

Ekwueme DU, Gery PG, Sun HR, Arica W, Ingrid JH, Temeka LF, Hazel DD. 2014. Health and economic impact of breast cancer. Breast cancer mortality in young women, 1970-2008. American Journal of Preventive Medicine, 46(1): 71-79.

Enow OG, Ndom P, Doh AS. 2012. Current cancer incidence and trends in Yaounde, Cameroon. Oncology, Gastroenterology and Hepatology Reports, 1(1): 58-63.

Fahad M. 2019. How much does a breast cancer treatment cost. DOI : https://bookimed.com/article/what-isthe-cost-of-breast-cancer. 174397

Ginsberg GM, Lauer JA, Zelle S, Bacten S, Baltussen R. 2012. Cost effectiveness of strategies to combat breast, cervical and colorectal cancer in Sub-Saharan Africa and South East Asia: mathematical modeling study. BMJ., (344): 614-618.

Gueye SM, Bawa KD, Mendes V, Toure CT, Moreau JC. 2009. Breast cancer screening in Dakar: Knowledge and practice of breast self-examination among a female population in Senegal. Review Med Brux, (30): 77-82.

Health Research Organisation (HERO) 
Cameroon. 2017. Breast cancer awareness month 2017 in Cameroon. DOI:

https://herocameroon.org/project/breastcancer-awareness-month-2017

International Agency for Research on Cancer WHO. Latest world cancer statistics: Global Cancer burden rise to 14.1 million new cases in 2012. Marked increase in breast cancers must be addressed. Press release No. 223, $12^{\text {th }}$ Dec. 2013.

Isara AR, Ojedokun CI. 2011. Knowledge of breast cancer and practice of breast selfexamination among female senior secondary school students in Abuja, Nigeria. Journal Prev. Med Hyg, (52): 186-190.

International Monetary Fund. 2015. GDP per capita (constant prices, national currency) for Cameroon. 1980-2012.

Joe-Nat CL. 2017. Epidemiology of Breast Cancer in Africa. DOI: https://oncologypro.esmo.org/content/ download/102746/1814743/2017

Kemfang JD, Yomi J, Kasia JM, Mayamba Y, Ekortarh AC, Vlastos G. 2011. Breast cancer profile in a group of parents followed up at the Radiation Therapy Unit of the Yaounde General Hospital, Cameroon. Obstetrics and Gynaecology International. Clinical study. DOI: http://dx.doi.org/10.1155/2011/143506

Marj PZ, Stanton RM. 2012. Breast cancer: Will treatment costs outpace effectiveness? Evidence-based Oncology. DOI:

https://www.com/journals/evidencebased-oncology.

Ministry of Public Health. 2017. Health analytical profile 2016 Cameroon. Ministry of Public Health, Cameroon, Yaounde.
National Cancer Control Committee. 2010. Information Guide. Ministry of Public Health, Cameroon.

National Cancer Control Committee. 2007. Information Guide. Ministry of Public Health, Cameroon.

Pinder J. 2015. Cost of breast cancer in the US: Cost of care. DOI: https://clearhealthcost.com/blog/ 2015/11/costs-breast-cancer-u-s-costscare

Stephanie S. 2013. Significant economic losses when young women die from breast cancer. American Journal of Preventive Medicine.

DOI:

https://medicalxpress.com/pdf 306148222.

Suh MA, Atashili J, Fuh EA, Eta VA. 2012. Breast self-examination and breast cancer awareness in women in developing countries: a survey of women in Buea, Cameroon. BMC Research Notes, (5): 627-633.

World Bank. 2016. National accounts data and OECD. National Accounts Data Files.

World Health Organization. 2015. Costeffectiveness thresholds - WHOCHOICE. Health Economics. https://www.healtheconomics.com/resou rce/cost.

World Health Organization Report. 2017. Cameroon-breast cancer. DOI: https://www.worldlifeexpectancy.com/ca meroon-breast-cancer. 